\title{
Characteristics, Knowledge, and Perception of Expectant Mothers About Preconception Preparations
}

\author{
$1^{\text {st }}$ Irma Linda \\ Faculty Public Health \\ Universitas Sumatera Utara \\ Medan, Indonesia \\ irmalinda65@gmail.com
}

\author{
$2^{\text {nd }}$ Heru Santosa \\ Faculty Public Health \\ Universitas Sumatera Utara \\ Medan, Indonesia \\ heru_php2@yahoo.com
}

\author{
$3^{\text {rd }}$ M. Fidel Ganis Siregar \\ Faculty of Medicine \\ Universitas Sumatera Utara \\ Medan, Indonesia \\ fgsiregal@gmail.com
}

\author{
$4^{\text {th }}$ Zulhaida Lubis \\ Faculty Public Health \\ Universitas Sumatera \\ Medan, Indonesia \\ zulhaida.lubis@usu.ac.id
}

Corresponding author: irmalinda65@gmail.com

\begin{abstract}
Health problems that should be observed in women before pregnancy are related to the state of the reproductive system, the status of sexually transmitted diseases, the state of nutritional status, physical and psychological disease problems. The condition should be followed up with the services provided in the health facilities to ensure the health status of women before conceiving in good condition, as it will affect the first 1000 days of life for children who started since the conception period until the toddler child.The type of research used is survey analytic with the cross-sectional study design approach. The research site is conducted at the Pancur Batu Sub District of Deli Serdang Regency Province of North Sumatera, research time in August and September in 2019. The population in the study is all expectant mothers who visit the Integrated Service Post and Public Health Center with a sample are 110 by taking total sampling. Analysis of independent variables (age, number of births, education level, and knowledge) to perception about preconception preparations used the Spearman test to determine the relationship and the size of the correlation. The results of the study of the perception of pregnant women about preconception preparation are $8,06(95 \%$ CI: 7,28 to 8,30$)$, with a standard deviation of 1,273 , the average value of the perception is inferred well. The average value of knowledge about the preconception preparations is 17,88 (95\% CI: 17,48 to 18,28) with the standard deviation 2,110 well concluded. Factors related to the perception about preconception preparations are the level of education with a value of $p=0.010$ and the correlation coefficient indicates the number $r=0.244$ which means it has a weak correlation strength and knowledge had a significant relationship with the perception about preconception preparations with a value of $\mathrm{p}=\mathbf{0 . 0 0 4}$ and correlation coefficient indicates the number $r=0.275$ which means it has a weak correlation strength that positively patterned
\end{abstract}

means the growing knowledge of mother the greater the perceived value. This means it is necessary to increase the knowledge of women of childbearing age about the need to prepare the physical and mental health of the Preconception by the related health workers.

Keywords: characteristics, knowledge, perception, Preconception preparations.

\section{INTRODUCTION}

Procedure before pregnancy (Preconception) is defined as a treatment consisting of healthy behavioral practices applied before Conception and thereby modifying the risk of biomedical, behavioral, and social outcomes for a better pregnancy. Growing recognition on the need for treatment of Preconception treatment series ranging from adolescence, prepregnancy, childbirth and the post-natal period, childhood, and through the reproductive age to increase the outcome of pregnancy, and reduction of maternal mortality and newborns. However, a wide gap exists in the treatment range due to an error perception that healthy behavior is only required during pregnancy. However, at that time, most women recognized their pregnancy: Most of the fetal organs have formed[1]. In 2013 the World Health Organization (WHO) showed that preconception care was relevant for all women of reproductive age. In high-income countries, the women postpone childbirth to the time when their fertility has decreased, whereas women in low-income countries will benefit from delaying pregnancy and the subsequent pregnancy distance. Because the most critical period for organ 
development occurs before many women know they are pregnant, the first contact with antenatal care is often late for advice on lifestyle changes that improve health. Besides, there is more evidence that the health and lifestyle of women, and also men, before conception can affect the outcome ofpregnancy. Globally, at least four out of ten women reported that they have not planned for their pregnancy well, highlighting the need for an approach across the population for evidence-based preconception care for women of childbearing age with chronic disease[2].Nowadays, many international health institutions recommend preparation and counseling activities during preconception (before pregnancy). These institutions produce recommendations related to identification modification due to reducing risk factors from the occurrence of pregnancy complications. This preconception screening has worked well in some countries, high-income countries such as Italy, the Netherlands, and the United States, or low and middleincome countries, such as Bangladesh, the Philippines, and Sri Lanka. WHO mentions that 4 out of 10 women in the world have had an unplanned pregnancy that resulted in essential health needs when pregnancy will be reduced to $40 \%$, at least as much as $20 \%$ of mothers suffer death due to deficiency Iron, perinatal mortality of $50 \%$ higher in mothers who give birth under the age of 20 years compared to mothers aged between 20 to 29 years[3] . Almost half or as much as 48.9 percent of pregnant women in Indonesia have anemia or blood deficiency, according to the results of basic health Research (RISKESDAS) in 2018. The percentage of pregnant women with anemia increased when compared with Riskesdas results in 2013 of 37.1 percent. From the 2018 data, the highest number of pregnant women with anemia at 15-24 years is 84.6 percent, 33.7 percent aged 25 to $34,33.6$ percent aged 35 to 44 , and 45 to 54 years old by 24 percent. While the data of the fertile time of women experiencing less chronic energy (KEK) thus shows positive trends compared to previous years. The proportion of the risk for women of childbearing age decreased compared to 2013, which is from 24.2 percent in women with fertile aged in 2013 to 17.3 percent in 2018. In addition to women of childbearing age did not conceive 20.8 percent in 2013 decreased so 14.5 percent in 2018[4].

Health problems that should be observed in women before pregnancy are related to the state of the reproductive system, the status of sexually transmitted diseases, the State of nutritional status, physical and psychological disease problems. This condition must be followed up with the services provided in the health facilities to ensure the health status of women before conceiving in good condition, as it will affect the first
1000 days of life for children who started since The conception period until the toddler[5]. Perception is a process preceded by sensing, which is a stimulus received by the individual through the receptor tool that is the sense. The sensory device is the link between the individual and the outside world.

Perception is a stimulus that is sensed by the individual, organized then interpreted so that the individual realizes and understands what is sensed. In other words, perception is a process that concerns the entry of messages or information into the human brain. Factors that play a role in the perception are 1) Attention, 2) Knowledge, and 3) How to think. Perception is an integrated state of the individual against the stimulus he receives. What is in individuals, thoughts, feelings, individual experiences will be actively influential in the perception process[6]. Borges, in his research found that there was a strong link between the adoption of preconception health measures and the planning status of pregnancy. Considering the relatively low proportion of pregnancies planned in Brazil, the women and spouses need to be encouraged to plan their reproductive lives. The results also show that not all women who plan their pregnancy carry through preconception measures, indicating that preconception care should be part of a routine action health service immediately[7]. From the results of the field survey conducted through interviews with pregnant mothers at the Gunung Tinggi Public Health Center Pancur Batu subdistrict that most pregnant women do not make preparations and plans before pregnancy occurs.

They started to prepare after they realized that they had been pregnant and that happened at a varied time for each pregnant woman. Based on the background above, researchers make the formulation of the problem of age relationship, education, and the number of parity with the perception of expectant mothers about the preconception preparation in the working area of Gunung Tinggi Public Health Center Pancur Batu District of Deli Serdang Regency.

The study aims:

A. Analyze the age relationship of pregnant women with a perception of the preconception preparation

$B$. Analyze the relationship number of births with the perception of the preconception preparation

$C$. Analyze the level of education relationship with perception of the preconception preparation

$D$. Analyze the relationship of knowledge with the perception of the preconception preparation 
Hypotheses in the study are:

A. There is an age relationship of expectant mothers with a perception of the preconception preparation

B. There is a relationship between the number of births with a perception of the preconception preparation

C. There is an education level relationship with the perception of the preconception preparation

D. There is a knowledge relationship with perception of the preconception preparation

\section{METHOD}

The type of research used is survey analytic with a cross- sectional study design approach. The research site was in Pancur Batu, Deli Serdang District, North Sumatra Province, and it had conducted in August and September 2019. The population in the study is all expectant mothers who visit the Integrated service post and Public Health Centre in the working area of Gunung Tinggi Public Health Center of Pancur Batu Sub-district of Deli Serdang Regency in August and September 2019

(Surveyapprovalnumber:1322/440/DS/II/2 019).

Samples of 110 expectant mothers, the way to take samples using a total sampling technique. The data collection process uses a questionnaire of 20 questions and is filled directly by the respondent. In this study, the measuring instrument that researchers used to measure variable values was a questionnaire that has previously been trialed. The data processing through editing, coding, processing, and cleaning. The type of data for characteristics are ordinals and for knowledge of numerical data. The Data type for the dependent variable (perception) uses the numerical form. Data is analyzed univariate and bivariate. Analysis of independent variables (age, number of births, education level, and knowledge) to perceptions of preconception preparations used the Spearman test to determine the relationship and the size of the correlation[8].

\section{RESULT}

\section{A. Research results}

To analyze the relationship characteristic, knowledge, and perception of expectant mothers about preconception preparations in the work area of the Gunung Tinggi Public Health Center district of Deli Serdang can be seen in the following table:

1. Univariate analysis

a) Age, Number of Birth, and Education Level
Table 1 The distribution of respondents by age, number of births, and level of education

\begin{tabular}{|c|c|c|c|c|c|c|}
\hline No & Categori & $\mathbf{F}$ & $\%$ & Mean & SD & $\begin{array}{l}95 \% \\
\text { CI }\end{array}$ \\
\hline \multirow[t]{5}{*}{1} & \multicolumn{6}{|l|}{ Age } \\
\hline & $<20$ years & 4 & 3,6 & 7.25 & 0.500 & $\begin{array}{l}6,45 \text { to } \\
8,05\end{array}$ \\
\hline & $20-35$ years & 87 & 79,1 & 8.06 & 1.306 & $\begin{array}{l}7,78 \text { to } \\
8,34\end{array}$ \\
\hline & $>35$ years & 19 & 17,3 & 8.26 & 1.195 & $\begin{array}{l}7,69 \text { to } \\
8,84\end{array}$ \\
\hline & Total & 110 & 100,0 & 8.06 & 1.273 & \\
\hline \multirow[t]{5}{*}{2} & \multicolumn{6}{|c|}{ Number of births } \\
\hline & 0 & 12 & 10,9 & 8,00 & 1.348 & $\begin{array}{l}7,14 \text { to } \\
8,86\end{array}$ \\
\hline & 1to3 children & 90 & 81,8 & 8,09 & 1.278 & $\begin{array}{l}7,82 \text { to } \\
8,36\end{array}$ \\
\hline & $>3$ children & 8 & 7,3 & 7,88 & 1.246 & $\begin{array}{l}6,83 \text { to } \\
8,92\end{array}$ \\
\hline & Total & 110 & 100,0 & & & \\
\hline \multirow[t]{5}{*}{3} & \multicolumn{6}{|c|}{ Education level } \\
\hline & $\begin{array}{l}\text { Low } \\
\text { education }\end{array}$ & 44 & 40,0 & 7,68 & 1.491 & $\begin{array}{l}7,23 \text { to } \\
8,14\end{array}$ \\
\hline & $\begin{array}{l}\text { Secondary } \\
\text { education }\end{array}$ & 56 & 50,9 & 8,23 & 1.062 & $\begin{array}{l}7,95 \text { to } \\
8,52\end{array}$ \\
\hline & $\begin{array}{l}\text { Higher } \\
\text { education }\end{array}$ & 10 & 9,1 & 8,80 & 0.789 & $\begin{array}{l}8,24 \text { to } \\
9,36\end{array}$ \\
\hline & Total & 110 & 100,0 & & & \\
\hline
\end{tabular}

The age distribution of respondents is mostly in the age group of $20-35$ years as much as $79.1 \%$, the age group $>35$ years is $19 \%$, and the age group $<20$ years is as much as $3.6 \%$. The number distribution of births of respondents with the number of 1 to 3 children was $81.8 \%$, the number that was not born was $10.9 \%$, and the number of births $>3$ children was $7.3 \%$.

The distribution of the education level of the respondents was mostly secondary education as $50.9 \%$, low education $40.0 \%$, and high education $9.1 \%$. The average perception of respondents in those with an age of $<20$ is to have a perceived value of 7.25 with a standard deviation of 0.500 . In those who have aged 20 to 35 years average perception value is 8.06 by the standard deviation of 1.306. In those aged $>35$ years the average value of perception is 8.26 with a standard deviation of 1.195 . The average perception value of respondents on those who have 0 birth amounts is 8.00 with a standard deviation of 1.348 . Those who have a birth amount of 1 to 3 children have an average perceived value of 8.09 with a standard deviation of 1.278. In those who have several births $>3$ children.

The average value of perception is 7.88 with a standard deviation of 1.246. The average value of perception on low-educated respondents (SD-SMP) is 7.68 with a standard deviation of 1.491. In medium-educated respondents (SMA) The average value of perception was 8.23 with a standard deviation of 1.062 . In high 
educated respondents (colleges) the average value of perception was 8.80 with a standard deviation of 0.789 .

b) Knowledge

Table 2. The average distribution of knowledge about the preparation of a pregnancy

\begin{tabular}{lcccc}
\hline Variable & Mean & SD & $\begin{array}{c}\text { Minimal } \\
\text { to } \\
\text { Maximal }\end{array}$ & $95 \%$ CI \\
\hline Knowledge & 17,88 & 2,110 & 12 to 20 & $\begin{array}{c}17,48 \\
\text { to } 18,28\end{array}$ \\
\hline
\end{tabular}

The results of the analysis showed that the mean value of knowledge was 17.88 (95\% CI: 17.48-18.28), with a standard deviation of 2.110 . The lowest knowledge score is 12 and the highest score is 20 . From the results of the interval estimation, it can conclude that $95 \%$ have been believed to have a maternal knowledge value between 17.48 and 18.28.

\section{c) Perception}

Table 3. The average distribution of perception about the preparation of a pregnancy

\begin{tabular}{lllll}
\hline Variable & Mean & SD & $\begin{array}{c}\text { Minimal } \\
\text { to } \\
\text { Maximal }\end{array}$ & \multicolumn{1}{c}{$\begin{array}{l}95 \% \\
\text { CI }\end{array}$} \\
\hline Percep tion & 8,06 & 1,273 & 2 to10 & $\begin{array}{l}7,82 \\
\text { to } 8,30\end{array}$ \\
\hline
\end{tabular}

The average value of perception was 8.06 (95\% CI: 7.28 - 8.30), with a standard deviation of 1.273 . The lowest perception value is 2 , the highest value is 10 , and from the results of the interval estimation, it can conclude that $95 \%$ have believed to mean that the perceived score of pregnant women about preparation before pregnancy ranges between 7.82- 8.30.

\section{Analysis of Bivariate}

For the results of the bivariate analysis on free variables (age, number of births, level of education) with a bound variable (the perception of preparation before pregnancy) can be seen in the following table: a) Perception by Characteristics

Table 4. .Relationship of Characteristic Variables (Age, Number of births, Education level) with Perception of Preconception Preparations

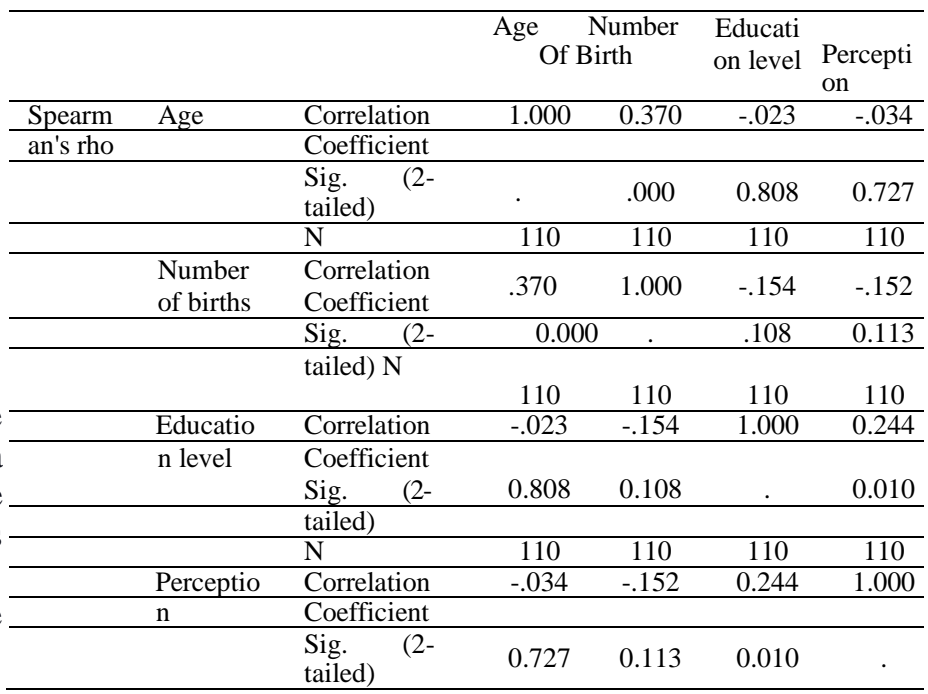

From the results of the bivariate analysis using Spearman test at alpha, 5\% obtained the result that characteristic variables for age and number of births did not have a significant correlation with the perception of preconception preparation, while the variable level of education had a significant correlation with the perception of preconception preparation with a value of $\mathrm{p}=0.010$ and the correlation coefficient showed a figure of $\mathrm{r}=0.244$ which means it has a weak correlation strength.

b) Perception by Knowledge

Table 5. The Relationship of Knowledge with Perception of Preconception Preparation

\begin{tabular}{|c|c|c|c|c|}
\hline & & & Perception & Knowledge \\
\hline \multirow[t]{6}{*}{$\begin{array}{l}\text { Spearma } \\
\text { n's rho }\end{array}$} & Perception & Correlation & 1.000 & 0.275 \\
\hline & & $\begin{array}{l}\text { Coefficient } \\
\text { Sig. (2-tailed) }\end{array}$ & $\cdot$ & 0.004 \\
\hline & & $\mathrm{N}$ & 110 & 110 \\
\hline & Knowledge & $\begin{array}{l}\text { Correlation } \\
\text { Coefficient } \\
\end{array}$ & 0.275 & 1.000 \\
\hline & & Sig. (2-tailed) & 0.004 & \\
\hline & & $\mathrm{N}$ & 110 & 110 \\
\hline
\end{tabular}

The results of the bivariate analysis using spearman test at alpha $5 \%$ found that knowledge variables have a significant correlation with variable perception of preconception preparation with a value of $\mathrm{p}=0.004$ and correlation coefficient indicates the number $\mathrm{r}=0.275$ which means it has a weak correlation strength. 


\section{DISCUSSION}

1. The characteristics of the correlation (age, number of births, and education level) with the perception of preparation time before pregnancy The results of the study obtained that most of the respondents were in the age group in the healthy reproductive period (20-35 years). Statistically test results, age variables have no significant relationship with variable perception of preconception preparation $(\mathrm{p}=0.727)$. At $20-35$ years old, the risk of health problems in pregnant women is at least $15 \%$. Besides, when viewed from the development of maturity, women in this age group have reproductive maturity, emotional and social aspects. Although at this time some women at the age of 21 are delaying marriage because it has not put a top priority on the new life. In principle, this age is an ideal age to conceive and give birth to reduce the fetal and maternal health risk. The results of data analysis in this study were mostly the number of births in a total of 1-3 children with a mean perception value of 8.09 on a standard deviation of 1.278. Statistical test results obtained $\mathrm{p}=0,113$ value, meaning that at Alpha $5 \%$ can conclude that there is no difference in the score of perception among the three groups of births. The perception of preparation before pregnancy has nothing to do with the number of births. So, this is maybe because the experience of pregnancy is considered a natural thing that happens to every pregnant woman, and each pregnancy has its character. With more pregnancy experiences, mothers with parity Multipara have expected to know more about the preparation before pregnancy to prevent the occurrence of risk in pregnancy. Then, this is the result of the experience and maturity of the pattern. Thus, the experience can lead to good perception and can affect the behavior of pregnant women. The results of bivariate data analysis through spearman test at alpha $5 \%$ found that there was no significant relationship between age, number of births with the perception of preconception preparation. Further analysis proves that the value of perception on each age group does not differ significantly. This is corresponding with the research conducted by Sara (2016), that there is no relationship between age and the perception about antenatal care examination (pvalue $0.556>0.05$ ) by midwives in the Central district of Demak[9]. This is not corresponding with the theory of Notoatmodjo (2010) which states that age is a life that is calculated from birth to recurrence. The more age, the level of maturity and the strength of a person will be more mature in thinking and working. In terms of belief, more mature people will be more trustworthy than people who are not too high in their maturity level. This is likely due to a person's perception of health in general, both regarding the importance of maintaining health, understanding of health problems, and health benefits for themselves and their surroundings. People who have a negative perception of health tend to low levels of obedience. In contrast, people who have a positive perception of health will tend to be more obedient to what health care professionals suggest[10].The quality family in the setting and planning of pregnancy can be influenced by many factors in terms of economic maturity, age of spouse, social influence of culture, environment, occupation, and health status of the couple[11]. According to Rahima in Siregar 2011, in the community still applies most of the husband and wife talk about the size of the family when they want to increase the number of children without touching the problem of readiness of the wife to receive a new pregnancy and this is what triggers unwanted pregnancy [11]. From the research results, it was found that the education level of the respondents was mostly middle school (SMA) with an average perceived value of 8.23 at a standard deviation of

Statistical test results obtained the variable level of education had a significant relationship with the perception of preconception preparation with a value of $\mathrm{p}=0.010$ and a value of $\mathrm{r}=0.244$ indicating weak growth strength. Pregnant women who have higher education with the perception about the preparation of time before pregnancy is also high. It is related to Notoatmodjo (2010) that education is a conscious effort to develop personality and ability in and of the school that lasts for a lifetime. The higher a person's qualification, the higher the awareness of his/her rights. The condition will increase the demands on the right to obtain information, the right to refuse or accept the treatment offered. The level of education relates to the ability of mothers to receive and absorb information about health by particularly in the prevention of pregnancy health problems [10].

2. Knowledge relationship with perception of preconception preparations From the results of the analysis, it obtained the average value of knowledge is 17,88 (95\% CI: $17,48-18,28$ ), with a standard deviation of 2.110. The lowest knowledge score is 12 and the highest score is 20 . From the results of the interval estimation, it can conclude that $95 \%$ have been believed to have a maternal knowledge value between 17.48 and 
18.28. The results of the bivariate analysis using the spearman test at alpha $5 \%$ found that knowledge variables have a significant relationship with variable perception of preconception preparation with a value of $p=0.004$ and correlation coefficient indicates the number $\mathrm{r}=0.275$ which means it has a weak correlation strength. These results indicate a tendency that the better the awareness of pregnant women about the preconception preparation will bring a better perception of preparation time before pregnancy. This is related to the results of the research conducted by Sara (2016), that there is a relationship between the characteristics of knowledge $(p$-value $=0,038)$ with the perception of pregnant women about antenatal care examination by midwives in the west of Demak District Puskesmas Dempet [9]. Sudarta (2014) in his research gained that there is a knowledge relationship with perception about the risk of $4 \mathrm{~T}$ in pregnancy in the health center of Danurejan I Yogyakarta[12]. Knowledge is one of the predisposition factors for the occurrence of one of behavior. Knowledge comes from an attempt to know in advance the stimuli to external objects through the senses and the interaction between oneself and the social environment, acquiring new knowledge of an object. It is from one of knowledge that will affect one of perception of what is seen and felt and will result in a change of behavior according to its perceptions [10]. The better the mother's knowledge about preparation before pregnancy, the mother- to-be can have a good perception of the importance of preparation before pregnancy to prevent maternal health problems. So that they can have a healthy pregnancy, give birth to children, and give birth.

\section{CONCLUSIONS}

The factors related to the perception of preconception preparations among pregnant women in the working area of the Gunung Tinggi Community Health Center were the level of education and knowledge, while the age and number of births had no relationship with the perception of preconception preparations. This means that it is necessary to increase the insight of women of childbearing age about the need to prepare the physical and mental health of the period preconception by related health workers. Health services before pregnancy in primary health facilities are expected to be the main promotive and preventive efforts so that every pregnancy is planned and prepared so that it will improve the quality of pregnancy and the newborn.

\section{ACKNOWLEDGMENT}

The author is grateful to Faculty of Health of the Universitas Sumatera Utara and the Head of Gunung Tinggi Health Center who have facilitated the implementation of this research.

\section{REFERENCES}

[1] midwifery concepts and ethicolegal practice of midwifery. 2010;

[2] Fahari,N.and Zolotor A. No Title. 2013.

[3] Decree of the Minister of Health of the Republic of Indonesia. No Title. Indonesia: 2010.

[4] balitbangkes K. No Title. 2018.

[5] Kementrian Kesehatan R. No Title. Jakarta: 2017.

[6] Walgito B. No Title. Yogyakarta: 2010.

[7] Borges ALV, dos Santos OA, Nascimento $N$ de C, Chofakian CB do N, Gomes-Sponholz FA. Preconception health behaviors associated with pregnancy planning status among Brazilian women. Rev da Esc Enferm 2016;50(2):208-15.

[8] Dahlan. No Title. Jakarta: 2018.

[9] Sera Juli. No Title. 2016.

[10] Notoatmodjo S. No Title. Jakarta: 2010.

[11] Siregar RY. No Title. 2011.

[12] Sudarta Wayan I. No Title. Yogyakarta: 2014 